\title{
O processo identificatório na prática de assistência ao aluno com dificuldades de inglês como LE no curso de Letras
}

\author{
The identification process within the practice \\ of assistance to the student that faces \\ difficulty in majoring in English as an FL
}

Maralice de Souza Neves*

Universidade Federal de Minas Gerais - UFMG

RESUMO: Este artigo apresenta parte de uma pesquisa com alunos sob supervisão de iniciação à docência que ministram aulas extraclasse para outros alunos com dificuldades em cursar as disciplinas iniciais de inglês em um curso de Letras. A partir de estudos do discurso que abraçam postulados da psicanálise, procura-se investigar momentos de identificação na experiência da docência. Desse modo, a identidade é concebida como sempre em construção, uma vez que a subjetividade está alienada à linguagem e determinada por condicionamentos histórico-culturais. Dentre as análises, exemplificam-se representações em relação ao bom aluno, ao bom professor, à noção de língua e ao tratamento do erro. Ao final, propõe-se que o processo de ensino e aprendizagem se dá por identificação, lembrando que as duas coisas acontecem no acaso dos desejos de aprender e ensinar.

PALAVRAS-CHAVE: Linguística Aplicada, representaçōes indentitárias, Análise do Discurso, Psicanálise.

ABSTRACT: In this paper I present results of a research with students under training supervision to teach extra classes to other students who have difficulty in following the regular English subjects in the beginning of their Major in Languages. Based on a theory of discourse informed by psychoanalytical propositions, I investigate moments of identification within their teaching experience. In this case, identities are conceived as being in constant construction, since subjectivity is alienated to language and determined by historical-cultural conditionings. The analyses indicate representations of the good student, the good teacher, their notion of knowing a language, and their treatment of errors. I end the paper proposing that the process of learning and teaching takes place within a process of identification and remembering that the two things happen by chance when the desire to teach meets the desire to learn. KEYWORDS: Applied linguistics, identitary representations, Discourse Analysis. Psychoanalysis.

*msneves@ufmg.br 


\section{Introdução}

Neste texto, proponho-me a discutir os modos de dizer que podem nos indicar como o sujeito que, no seu processo de dominar e ensinar a língua em seu trabalho de dimensão imaginária e simbólica, passa primordialmente por complexos desarranjos identificatórios. Ele não só aprende um código utilizandose de instrumentos, de modo a usar a língua, mas, sobretudo, põe em jogo a língua materna e/ou nacional em encontros/confrontos com a Língua Estrangeira (LE), bem como com seu próprio processo de vir a ser professor dessa LE. Farei análises de um corpus constituído de respostas a entrevistas, depoimentos e notas de campo obtidas de monitores da graduação lecionando aulas preparadas para alunos das disciplinas básicas necessárias à Habilitação em Inglês (modalidade licenciatura) de uma Faculdade de Letras em uma universidade pública de Minas Gerais. O programa de monitoria visa a possibilitar a prática da língua inglesa (LI) para alunos com dificuldades em acompanhar essa habilitação. ${ }^{1}$

O objetivo da pesquisa que gera este artigo foi investigar momentos da constituição identitária dos sujeitos-alunos em formação para professor e que, portanto, ministram as aulas em regime de monitoria. O projeto no qual se inserem é nomeado Para o desenvolvimento de habilidades em lingua inglesa, que, ao ser criado em 2002, visava a proporcionar, em primeiro lugar, a oportunidade de desenvolvimento didático-pedagógico de bolsistas, que na época faziam parte do Programa de Iniciação à Docência da Pró-Reitoria de Graduação da UFMG (PID) e de bolsistas voluntários do sub-projeto denominado Núcleo de AutoInstrução em Língua Inglesa (NAILI). ${ }^{2}$ Em segundo lugar, visava a suprir

${ }^{1}$ Projeto Processo discursivo e identificaçôes na aprendizagem de inglês como LE na universidade: práticas de assistência ao aluno com dificuldades, financiado pela bolsa de recém-doutor da Pró-Reitoria de Pesquisa da UFMG no período de 2004 a 2007. Este projeto contou com a participação do aluno de Iniciação Científica (voluntário) (voluntário) Estevão Carvalho Batista.

${ }^{2} \mathrm{O}$ projeto PID estava sob a responsabilidade da Pró-Reitoria de Graduação e o subprojeto NAILI recebeu apoio da FALE/UFMG, sendo que ambos foram coordenados pelas Professoras Herzila Bastos (2002-2004), e Herzila Bastos e Maralice Neves (2004-2007). O subprojeto NAILI foi necessário porque alguns alunos ingressantes no Curso de Letras que queriam aulas de inglês apresentavam nível de proficiência muito abaixo daqueles a quem o Projeto PID se destinava a ajudar. Dessa forma, os novos monitores do subprojeto passaram a atender a esse público. Agradeço à professora Herzila a cuidadosa leitura e valiosa contribuição com considerações importantes para este texto. 
atividades extraclasse para os alunos de inglês que encontravam dificuldades ao cursar as disciplinas básicas de LI ou ainda não se encontravam no nível de aprendizagem requerido para cursálas, uma vez que essas disciplinas se iniciam a partir do nível considerado intermediário. Atualmente, o estágio de bolsistas é nomeado Monitoria de Línguas (inglês, espanhol, alemão, francês e italiano), mas o acompanhamento dos monitores de inglês, especificamente, continua sendo feito nos moldes do PID-NAILI inicial.

Como suporte teórico-metodológico, utilizo conceitos da Análise do Discurso $(\mathrm{AD})$ de origem francesa, sobretudo as elaborações de Michel Pêcheux, cujos estudos, em sua terceira fase, abrigam postulados do campo da psicanálise. Esses estudos do discurso pressupõem a concepção de sujeito do inconsciente constituído como uma linguagem. Parto da posição epistemológica de que a linguagem é efeito de sentidos entre os sujeitos (PÊCHEUX,1995), isto é, o sentido se faz em suas relações. Desse modo, a atribuição de sentidos não funciona no nível da intenção, mas através de uma intersubjetividade inconsciente que põe em jogo as contradições da constituição histórica dos sujeitos. Portanto, a noção de sujeito uno, centrado e intencional que está suposta na prática de ensino comunicativo adotado na instituição onde constituo o meu corpus será aqui problematizada, já que concebo esse sujeito como desejante, descentrado, constituído pela linguagem e primordialmente via identificações. Assim, na ilusão de se comunicar com o outro, o sujeito se vềàs voltas com efeitos de sentido que se mostram no incessante deslize dos sentidos, nos equívocos e nas contradições.

Iniciarei com um breve histórico sobre o que motivou a pesquisa para, em seguida, enfocar os pressupostos teóricos e categorias que nortearão os registros analisados.

\section{Como tudo começou...}

As universidades públicas vêm mostrando empenho em criar mecanismos de permanência do aluno, assim como também têm enfrentado o desafio de aumentar o número de vagas e incluir cotas étnicas. Sendo participante do projeto de Iniciação à Docência acima mencionado, busquei compreender e problematizar o trabalho de formação identitária, ou melhor, as formas de representação de si e do outro no discurso, dos alunos envolvidos no processo de aprendizagem de inglês como língua estrangeira (ILE) na Faculdade de Letras. Muitos chegam à universidade sem a formação básica consistente com 
o início de um curso em nível intermediário. Diante dessa situação, os professores da Habilitação Inglês se viram diante da contradição de buscar melhorar o nível de seus formandos, exigindo-lhes um conhecimento prévio da língua trazidos do Ensino Básico e, ao mesmo tempo, não lhes retirar o direito de seguirem o curso da língua que escolheram. Os projetos de Iniciação à Docência foram então criados diante da injunção de possibilitar aos alunos que não estão no nível de início do curso o efeito de que podem conseguir alcançá-lo ou melhorar seu desempenho ao buscarem ajuda. Ao mesmo tempo, é possibilitado ao aluno já em formação adiantada na sua Habilitação exercer atividade docente, a fim de trabalhar a sua identidade de professor.

Nesta pesquisa, contei com a colaboração de um aluno voluntário em Iniciação Científica (IC), que fez observaçõos de aulas, conduziu entrevistas semi-estruturadas e tomou depoimentos $\mathrm{AREDA}^{3}$ dos três monitores em atividade. Esse aluno participou também das reuniões entre os monitores para preparação de aulas e correção de "testes de nivelamento" de inglês aplicados no primeiro período. ${ }^{4}$ Para se ter conhecimento do nível linguístico em que se encontram os alunos iniciantes, a coordenação do projeto de Iniciação à Docência promove a aplicação de testes de proficiência e os monitores são acionados para ajudarem na aferição. Essas provas são de múltipla escolha, mas é exigida a redação de um parágrafo com o tema oferecido na hora da prova.

Para apresentar esta análise, exporei um recorte obtido dos depoimentos dos monitores e de algumas conversas entre eles durante algumas reuniōes. Enunciados desse recorte do corpus nos remetem a identificaçôes flagradas no discurso: a) em relação a si como aprendizes de ILE; b) em relação a si como monitoresprofessores; c) em relação à imagem que fazem dos seus potenciais alunos.

\section{Princípios teóricos e categorias de análise}

É fundamental iniciar com a noção de sujeito que, assim como AuthierRevuz (2004) e Teixeira (2005), entendo ser crucial, uma vez que, nessa

\footnotetext{
${ }^{3} \mathrm{O}$ roteiro AREDA - Análise de Ressonâncias Discursivas em depoimentos Abertos (SERRANI, 1998) contém perguntas abertas cujas respostas são gravadas em áudio, estando os enunciadores sozinhos e à vontade.

${ }^{4}$ Acrescento que o referido aluno tornou-se monitor e, a partir de sua inserção no grupo, deixou de obter anotaçóes das reuniōes e aulas. Os depoimentos de cada monitor, entretanto, foram feitos quando o aluno já trabalhava com eles.
} 
concepção, o sujeito não é concebido como indivíduo, indiviso e consciente de seus desejos, mas como posição enunciativa, constituído nas/pelas práticas discursivas (FOUCAULT, 1985). É também sujeito-efeito, uma vez que é efeito do inconsciente e das filiações históricas do sentido que lhe retiram o domínio do seu ser e de seu dizer. Tanto na dimensão do ser, quanto na do dizer a alteridade, ele se faz condição de existência via identificação, primeiro a uma imagem proposta pelo outro e, em seguida, a uma identificação ao significante, como, por exemplo, o filho se identificar com traços significantes dos pais. Pela identificação, o sujeito se funda como desejante, uma vez que, segundo a psicanálise, ele é instado pela pulsão ${ }^{5}$ a sempre se reorganizar subjetivamente, em eterna construção identitária, sempre por vir (LACAN, citado por TEIXEIRA, 2005). Ressalto ainda que, ao falar, o sujeito revela posições enunciativas através de predicações (REVUZ, 1998; GRIGOLETTO, 2003), como veremos nas análises.

Uma vez que a noção de identidade, em si tomada como estável, é deslocada para a de identificação em psicanálise, ressalto que o que é apreendido são pontos de apego temporário às posiçóes-de-sujeito construídas pelas práticas discursivas. A unidade e homegeneidade interna da identidade é ilusória (HALL, 2000).

Desenvolvendo com maior profundidade essa questão, uma primeira noção da identificação opera na dimensão da representação de unidade do locutor na condição de Eu (ego) ideal (eu do desejo materno), estruturado na tentativa de corresponder à imagem, primeiramente, da mãe, e, depois, dos outros, no âmbito social. É, portanto, entendida como representação do ser, ou, melhor dizendo, é o que permite ao sujeito se dizer na primeira pessoa: "eu sou assim”. Por seu lado, essa noção também carrega a marca simbólica a partir da qual o sujeito adquire sua singularidade (não sua unidade). Enfatiza a referência ao dizer (TEIXEIRA, 2005). É a dimensão de um ideal do eu, em que um sujeito se apropria de um traço significante do outro que ele "copia" e que melhor caracteriza esse outro, como, por exemplo, ser autoritário como o pai; ser forte como a mãe. Cabe completar que "é apenas momentaneamente

${ }^{5}$ De modo muito simplificado, podemos dizer que a pulsão é como uma máquina que visa a fazer algo no corpo para descarregar uma energia sexual. Para Freud (1905), esse quantum de energia é diferente para cada pessoa, mas não existe corpo humano sem pulsão. A pulsão busca um gozo e para isso necessita do campo do outro. Na operação de satisfação da pulsão, o gozo não é pleno, sempre sobra algum resto, o campo da falta. Por isso a pulsão é parcial. Trata-se do domínio da falta. 
que se podem flagrar pontos no discurso que remetem a identificações sempre inconscientes, introjetadas a partir do outro, mas que, por já estarem lá, provocam reações, atitudes de recusa ou de aproximação" (CORACINI, 2003, p. 15). A noção de movimento, de mutação, é, portanto, decisiva quando falamos de posições identitárias, aqui tomadas nas representações, já que se trata de um processo identificatório. Nesse processo, há ainda que considerar a identificação ao desejo inconsciente (RIOLFI; ALAMINOS, 2007, citando LACAN, 1961, 1962), quando o que desejar vai sendo reintroduzido sempre que o sujeito se depara com a falta constitutiva. Na perspectiva dos Estudos Culturais, Woodward (2000) ressalta, a partir da contribuição também lacaniana para os estudos sobre identidade, o reconhecimento da diferença sexual, sendo que é a partir daí que a criança assume uma identidade de gênero. A criança é obrigada a reconhecer no Falo o significante tanto do poder quanto da diferença. A entrada do menino na linguagem se faz de modo "privilegiado" em relação à menina. Esta última já é posicionada como faltante. Assim, para Lacan (1985), a divisão por gênero só se sustenta no semblante, no que parece ser homem ou mulher. $\mathrm{O}$ que temos é o corpo submetido à linguagem indiferentemente do gênero, ou seja, é o corpo regido pelo gozo fálico. Veremos que essas considerações serão relevantes ao investigarmos as posições tomadas pelos enunciadores desta pesquisa, duas alunas ( $\mathrm{AP} \mathrm{e} \mathrm{Am}$ ) e dois alunos $(\mathrm{Me} \mathrm{H})$.

Transpondo essas considerações para a situação da formação do aluno, ao pensarmos em identificação do aluno com o professor, podemos dizer, a partir de Garcia (2001), que, a princípio, trata-se de uma ligação amorosa entre mestre e aluno facilitadora da compreensão entre ambos, que vêm, portanto, a formar um par: a relação professor / aluno. Entretanto, essa identificação se faz por força de um traço, e com um traço não se realiza um par, uma totalidade, pois "o traço não é amor, nem imitação, nem identidade. O traço é apropriação. Em vez de compreensão, harmonia, há disparidade, dissonância, a partir da operação de identificação" (GARCIA, 2001, p. 30). Não há, portanto, o princípio da cooperação facilitadora de uma tarefa de aprendizagem, mas o que Garcia chama de fidelidade ao acontecimento ${ }^{6}$ amoroso, político e científico, e que eu chamaria de fidelidade, a partir de Pêcheux (2002), às "coisas-a-saber"

\footnotetext{
${ }^{6} \mathrm{O}$ acontecimento aqui deve ser entendido não como um fato resultante de uma constatação, mas algo que surpreende; que é mesmo sinal de disfuncionamento no sistema (GARCIA, 2001). Enfim, algo que promove uma ruptura no esquema vigente e nos toma de surpresa.
} 
significantes. Não se trata, enfim, de uma apropriação que o professor possa fazer do aluno, no caso, por exemplo, de "saber o que ele deve saber", mas, sim, de um espaço vazio (onde eu acredito que supostamente entram os significantes das coisas-a-saber por força do encontro do desejo de ensinar com o desejo de aprender) no qual impera o acaso, pois o professor não sabe o que o aluno deseja saber, mas o aluno supóe que o saber que ele deseja está no professor (MENDONÇA FILHO, 2001) e, assim, busca, primeiramente, ser como esse professor.

Na relação que faço entre a Psicanálise e a Análise de Discurso, considero ainda importante a noção de "formaçôes imaginárias" que, para Pêcheux, estabelecem as condiçōes de produção dos discursos, ou seja, no contexto e situação do discurso, são as imagens que o sujeito tem de si, do outro e do referente em relações de sentidos, de forças e de antecipação, ressignificadas pelo já citado conceito da Psicanálise sobre identificação: o Eu-ideal alienante e estruturante. Esse Eu-ideal, então, se constitui no imaginário como uma identidade unificada, mas esse "sujeito como um todo" é o efeito clivado, faltoso e desejante do inconsciente que pertence ao simbólico e à ordem imaginária.

Vale lembrar que esse sujeito faltoso, entendendo-se como uma identidade unificada, atua em um contexto situacional das práticas discursivas que pressupõe a instituição de onde emerge um discurso; de onde ele é produzido. Essa instituição pode ser física (como escolas, presídios etc) ou "abstrata" (como casamento, por exemplo).

Cabe operar também com a noção de formação discursiva (FD) como possibilidade de descrever, num certo número de enunciados, semelhante sistema de dispersão, e definir uma regularidade entre os objetos, os tipos de enunciação, os conceitos, as escolhas temáticas (FOUCAULT, 1997). Uma FD, segundo Pêcheux (1995), é "constitutivamente frequentada por seu outro", o que abre para a entrada do conceito de interdiscurso, esse "outro" da FD, seu exterior específico, composto também por outras FDs. Nas análises que apresento buscarei apontar formulaçôes que se repetem no discurso dos depoentes. Observarei a repetição de determinadas marcas linguísticodiscursivas que constroem a representação de um sentido predominante e que Serrani (2001) nomeou ressonâncias discursivas. As ressonâncias se relacionam à noção de formação discursiva (FD), pois permitem levantar hipóteses que relacionem os processos sócio-históricos e suas respectivas discursividades. Observarei a repetição de construções que funcionam parafrasticamente, modos de enunciar, itens lexicais representados como semanticamente equivalentes. 
Concomitantemente, a noção de interdiscurso é necessária, uma vez que tudo que é nomeado está numa rede de valores e sentidos e estes estão vinculados diretamente a vivências e memórias discursivas que atravessam todos os sujeitos. Temos a ilusão discursiva necessária que dizemos tudo o que queremos, uma vez que o dito depende do que pode ou não se dizer em um determinado contexto, conforme os condicionamentos histórico-culturais. Paralelamente, Lacan (1998) nos aponta a alienação do sujeito à linguagem, uma vez que o sujeito não é causa da linguagem, mas é causado por ela. É um fala-ser (parlêtre), constituído no inconsciente e alienado a ele, um sujeito cujo desejo se faz na palavra endereçada ao outro para estabelecer laço social.

Ao considerar a alteridade, esse outro que frequenta e constitui o sujeito e o interdiscurso, Authier-Revuz $(1998,2004)$ apontou categorias de heterogeneidade ou não-coincidência do dizer, as quais mobilizarei na análise. A autora distingue a heterogeneidade mostrada da heterogeneidade constitutiva, mas não as separa. A heterogeneidade mostrada é a representação que o locutor dá (e dá-se) de sua enunciação. Estrutura material polifônica, dialógica, atravessada pelo inconsciente. A heterogeneidade constitutiva refere-se aos processos reais de constituição de um discurso, não-localizável, não-representável. $\mathrm{Na}$ heterogeneidade constitutiva pensa-se a alteridade como condição de existência do discurso de um sujeito que não é fonte primeira do seu dizer. "Há sempre um 'isso' que fala antes, em outro lugar e que instaura efeitos de sentido" (TEIXEIRA, 2005, p. 184, citando PÊCHEUX, 1995; AUTHIER-REVUZ, 1978).

Segundo Authier-Revuz (2004), apesar da constatação dos DOIS PLANOS, eles não se relacionam:

[...] a heterogeneidade mostrada não é um espelho, no discurso, da heterogeneidade constitutiva do discurso; ela também não é 'independente': ela corresponde a uma forma de negociação necessária do sujeito falante com essa heterogeneidade constitutiva - inelutável, mas que lhe é necessário desconhecer; assim, a forma 'normal' dessa negociação se assemelha ao mecanismo da denegação (p.71-72).

Para a autora (p. 72, citando FREUD, 1925), “a denegação é um meio de tomar conhecimento do recalcado." É através das marcas de heterogeneidade mostrada designando o outro localizadamente que o sujeito empenha-se em fortalecer o estatuto do um, sendo que a heterogeneidade mostrada é considerada como um modo de denegação da heterogeneidade constitutiva que depende do outro no um. 
Por seu lado, Serrani (2006, p. 90) propõe que, pelas regularidades enunciativas, podem-se apontar FDs ou modalizações destas quando se observam:

b) a) itens lexicais de uma mesma família de palavras ou itens de diferentes raízes lexicais apresentados no discurso como semanticamente equivalentes, construções que funcionam parafrasticamente;

c) modos de enunciar presentes no discurso (tais como o modo determinado e o modo indeterminado de enunciar; o modo de definir por negaçôes, ou por afirmações modalizadas ou categóricas, o modo de acréscimos contingentes através das incisas, glosas etc.).

Veremos agora as representaçóes aprendidas nas análises que nos apontam para momentos de identificação descritos abaixo em três instâncias: a) em relação a si como aprendizes de ILE; b) em relação a si como monitoresprofessores; c) em relação à imagem que fazem dos seus potenciais alunos.

\section{Representações no discurso dos monitores $\mathrm{M}, \mathrm{AP}, \mathrm{H}$, em relação a si como aprendizes e monitores-professores ${ }^{7}$}

\section{- Em relação a si como alunos-aprendizes}

\section{a) O bom aluno}

Authier-Revuz $(1998,2004)$ aponta, no funcionamento da enunciação, formas meta-enunciativas de modalização autonímica a serem interpretadas como referência a um outro discurso. No excerto abaixo, os dizeres de $\mathrm{M}$ são realizados no diálogo com a sua própria palavra do "ser bom aluno" e do "estudar inglês", o ponto onde a enunciação se apresenta afetada por um heterogêneo que lhe escapa (...como eu posso dizer...). Vejamos:

M1: /como eu já tinha feito curso anterior a faculdade/ né/ curso de expressão livre/ eh /eu já tinha /eh/ estudado inglês antes da faculdade/ então já era uma coisa que era/ como é que eu posso dizer/ já era uma coisa que eu queria realmente pra $\mathrm{mim} /$ estudar inglês na faculdade.

\footnotetext{
${ }^{7}$ Legenda das transcrições e marcas para análise: / pausa breve; // pausa mais longa; ( ) comentários do pesquisador ou descrição de gestos não-verbais; negrito = posições enunciativas; itálico $=$ modos de enunciar em análise.
} 
M2: /e enquanto aluno de inglês/ por causa desta minha identida- dessa minha identificação com a língua/ eu me considero um bom aluno de inglês/ eh/ porque realmente/ como que eu posso dizer/ porque é uma coisa que eu quero realmente fazer/ então eu sou bom/ o que eu quero fazer/ quero estudar inglês.

Em uma modalização interrogativa, em que o enunciado não está imediatamente disponível, a palavra falta e marca, na dificuldade de elaboração, a busca de ganhar um tempo "que se corporifica no exercício da linguagem" para então se fixar na modalização do advérbio "realmente" e firmar o momento da identificação com o querer e o ser um bom aluno e bom professor. Nesse movimento identificatório, é possível vislumbrar o sujeito na busca por sua unidade no modelo do bom aluno e no modelo do mestre que ensina na faculdade. Este último tomado como completo, cujo desejo o aluno acredita também desejar. Percebem-se aí momentos de identificação importantes, porque, ao procurar reproduzir esse professor de uma língua, idealizado no grupo de estudos, busca-se uma saída coletiva de reconhecimento social no grupo e na universidade.

\section{b) Uma aluna não tão aplicada}

Já a monitora AP, numa outra forma de modalização autonímica, constrói o seu discurso identificando-se como aplicada, e em seguida, como efeito opacificante do discurso, produz a incisa, que, segundo Serrani (1998), citando Haroche (1981), tem o efeito não só de desnível sintático, mas de materialização de um movimento identificatório contrário: não o tanto que eu deveria ser. A modalização deôntica, deveria, aponta para o conflito entre o desejo (que não se dá a ver, posto que é falta) e a demanda de identificação com o desejo do grupo, do bom aluno, reafirmada nas adversativas mas... ("de ser mais aplicada, de chegar lá...”).

AP: /como aluno de inglês/ aluna né/ eu me considero//aplicada/ não o tanto que eu deveria ser/ mas aplicada/ ainda tenho muita coisa que aprender Imas eu vou chegar lá.

Em outras palavras, a tomada de posição enunciativa de AP denuncia um vacilo identificatório com o ideal de bom aluno ou até de native-like, dando lugar ao espaço vazio de um não-saber. 


\section{c) Oaluno native-like}

H1:/ eu me considero um bom aluno porque eu procuro me informar sempre/ eu não me contento com o que eu sei/ eu sempre acho que preciso aprender mais// ah/ quando eu deparo com alguma dificuldade /eu /eu procuro alguém que eu sei que conhece mais que do eu/ procuro algum professor de inglês/ ou algum falante nativo pra pra saber se aquela pessoa pode resolver este problema/

$\mathrm{H} 2$ : ah/ eu acho que todos os alunos que estão se habilitando em língua estrangeira/ ah /tem esta dificuldade de ser /de ter um nível de proficiência excelente /assim/ native like/

$\mathrm{H}$ se posiciona identificado com a necessidade de procurar saber mais, $\mathrm{e}$ no lapso onde troca ter por ser, manifesta, no equívoco, um traço de singularidade, no desejo de ser native like, como se sobrepondo à possibilidade de ter um nivel de proficiência excelente. Considerando a heterogeneidade estrutural das formaçōes discursivas, sempre frequentadas por um outro interdiscursivo (PÊCHEUX, 1995; AUTHIER-REVUZ, 2004), cabe apontar também nesse dizer a ressonância de uma FD que Neves (2002) nomeou Excludente, pois abarca regularidades enunciativas que valorizam a excelência, a perfeição, caracterizada no ser nativo ou native-like e excluindo a falta, o erro, a nãoexcelência aqui caracterizada na dificuldade de ter nível de proficiência excelente.

\section{d) O aluno que "corre atrás"}

Há ressonância no que se refere à representação da dificuldade de alcançar um nível de excelência observável no discurso dos três monitores através da ressonância, na repetição da expressão "correr atrás", tanto no discurso sobre si quanto na imagem que têm do bom aluno:

M: /acho que a primeira coisa é estar consciente das dificuldades/ quais são elas/ e tentar sanar estas dificuldades/ seja através de grupos de estudos/ seja através de monitorias/ seja através de aulas particulares/ correr atrás /e ver como é possível sanar essas dificuldades/

AP1: /várias vezes durante o meu aprendizado na língua/ eu enfrentei essas dificuldades/ e eu tive que correr atrás/ curso extra/ uma maior exposição à língua/

AP2: /eu não tenho escrito academicamente em inglês/ então eu tenho que voltar correr atrás disto/

AP3: /o básico das características de um bom aluno são o interesse em aprender/ essa boa vontade de estar em sala de aulal ser um pouco aplicadol claro/ correr atrás do conhecimento/ 
AP4: /sempre correr atrás do seu problema/ tem que tentar detectar onde tá o problema/ e correr atrás/ no mais expor a dificuldade/ pra alguém que possa ajudá-lo/

$\mathrm{H}$ : Bom aluno eu considero que seja aquele que corre atrás/ que procura tirar as suas duvidas/ que procura aprender/ que procura melhorar/

A expressão "correr atrás” é elíptica, pois se refere à expressão “correr atrás do prejuízo", que também é elíptica em si, já que se refere não ao prejuízo e, sim, à sua anulação. Não se sabe da origem dessa expressão, mas é muito usada no meio esportivo, principalmente no futebol. O dicionário Aurélio não a contempla, mas seu uso corrente dá a "idéia de decisão, de movimento, de ir à luta" ${ }^{8}$ Nessas condições de produção dos enunciados, esse significante é repetido por todos os monitores, mas seus sentidos tendem a deslizar conforme a representação que cada monitor tem de si. M e H têm imagens de bons alunos e correm atrás de sanar dificuldades, melhorar, aperfeiçoar o que já sabem. AP, entretanto, tem de si uma imagem de aluna não tão aplicada e corre atrás de ser um pouco aplicada, de ter boa vontade de estar em sala de aula, marcando, assim, a representação de sua condição (feminina) faltosa.

\section{Em relação a si como professores-monitores no Projeto de Iniciação à Docência}

Nos enunciados dos três monitores, veremos, em seguida, suas representaçôes de si como professores idealizados e também como monitores, no lugar de aspirantes a professores. Surgem três imagens do professor idealizado: aquela do professor afetuoso e próximo ao aluno, aquela do professor que corre o risco de se perder, de não ser bem-sucedido e, finalmente, a do professor que tem embasamento teórico sólido.

\section{a) Um professor próximo ao aluno}

No discurso de $\mathrm{M}$ a seguir, ressoam os itens querer, ter vontade com referência a ser professor, na modalização interrogativa (como eu posso explicar) (AUTHIER-REVUZ, 2004), na negativa (não ser por conveniência), bem como no equívoco das palavras (por outras ocasi-), e na incisa (outra característica),

\footnotetext{
${ }^{8}$ Ensaio não assinado, veiculado no jornal Vale paraibano de São José dos Campos, SP, em 1998. Disponível em: <http://jornal.valeparaibano.com.br/1998/07/05/ social/leitura.html>. Acesso em: 20 jan. 2008.
} 
todas com a função de ganhar tempo para fixar o dizer nas identificações: querer ser professor e saber dividir o papel com o aluno. Já na representação de si como monitor, a identificação referente a dividir o papel com o aluno ressoa parafrasticamente (SERRANI, 2001), apontando uma regularidade de igualdade e de proximidade do professor com o aluno nas imagens que ele tem de ser professor, do que é ser monitor e aluno. Esta identificação é, no entanto, desestabilizada através da incisa (não teoricamente lógico):

M: /eh//comprometimento com a profissão em si/ como eu posso explicarl querer estar ali/ querer ser professor/ não ser por conveniência /ou por outras ocasi-outros contextos/ querer ser um professor/ ter vontade de ser professor/ estar/ outra característica é estar aberto também/ a mudanças/ a outras perspectivas/ saber que cada turma vai ser diferente/ saber dividir o seu papel com o aluno/ também muito importante//eh /do monitor/ eu espero além dessas todas do professor/ eu espero ter um coleguismo realmente/ é preciso mostrar pro aluno que eles estão num mesmo/ que é muito mais/ que $o$ professor está no mesmo patamarl não teoricamente lógicol mas o monitor/ além dessas todas/ espero esta proximidade/ esta proximidade com o alunol

\section{b) Um professor que pode se perder}

Abaixo, a enunciadora AP repete a construção que ressoa como efeito de discurso dela como aluna (perder o fio da meada, se perder, fico meio perdida), distanciando-se de uma identificação com a imagem do professor ao qual ela atribui a imagem contrária, através da negação representada pela preposição designadora de falta sem. Essa representação de ficar perdida, de se perder, poder não ter todas as respostas, não saber responder, é reforçada pelo lugar que ela ocupa como monitora, que o lapso (como aluna) vem marcar como muito mais próxima de se identificar com a imagem de aluna (daquela que não sabe e pode se perder) do que com a imagem de professora (que não pode se perder).

AP: /eh ser muito sensível pra observar as necessidades de seus alunos/ sem com isso perder o fio da meada/ porque é muito fácil você olhar cada um/ você acaba se perdendo um pouco// então tentar fazer sem se perder// e no mais/ter um bom conhecimento da língua/ ter uma pronúncia legal/ estar sempre interessado em buscar aprender//bom, como monitora/ eu posso dizer que o que eu esperaria de mim como alunal como monitoral é assim / o monitor pode não ter todas as respostas/ que é o que acontece comigo na sala de aula/ fico meio perdida/ não sei responder alguma coisa/ mas esta é a vantagem de correr sempre atrás/ de levar mesmo aquela informação ao aluno/ nél 


\section{c) Um professor que sabe tudo}

No discurso de $\mathrm{H}$ abaixo, a imagem que ele tem do professor também é a daquele que detém o saber teórico, que explica os erros do aluno. Uma posição identificatória que, ao mesmo tempo em que marca seu desejo de perfeição, de não haver erros, personificada na imagem do professor, ela se identifica com a possibilidade de errar na condição de monitor, experimentador, que faz testes, experiências e pode errar. Poderíamos dizer que há uma oscilação identificatória entre as FD Excludente, que exclui a possibilidade de errar e exalta a perfeição, e a FD Inclusiva, que dá margem à falta, ao erro, à experimentação (NEVES, 2002):

H: /ter um embasamento teórico bem sólido/ entender como funciona/ de onde que vem os erros que os alunos cometem/ o porque d'ele tá cometendo aquele erro/ seja da sintaxe/ ou da fonologia/ ou na semântica/ $\mathrm{ah} /$ entender bem /ah/a lingua nativa daquele aluno/ pra poder entender a origem daqueles erros/ eh/ até mesmo sócio culturalmente/ eh / o professor tem que estar com a mente bem aberta pra isto/ não apenas tratar o aluno como estando errado ou certo/ tem toda uma série de fatores que influencia isto// bom/ e o monitor/eh / seria como se fosse um laboratório pra esse aluno que está se formando em licenciatura/ eh/ é de extrema importância por que ali a gente faz o teste/ tem o apoio teórico das coordenadoras/ eh / então faz experiência / e/vê o que dá certo e o que não dá/

Podemos ver, também, nas sequências discursivas dos três enunciadores, uma ressonância de distanciamento identificatório com a imagem de si como professores e uma aproximação com a imagem que têm de si como alunos quando tomam a posição de monitores. São sujeitos que, ao se constituírem por suas práticas discursivas de monitores, inevitavelmente vão se representando via identificaçôes imaginárias e simbólicas, ora com o professor que desejam ser, ora com os alunos que ainda são. Lembrando que temos a ilusão discursiva necessária de dizer tudo o que queremos, uma vez que o dito depende do que pode ou não se dizer em um determinado contexto, conforme os condicionamentos histórico-culturais, essas sequências foram produzidas em depoimentos AREDA organizados e monitorados por um aluno de IC, que vinha observando a prática de monitoria. Os monitores sabiam que suas respostas seriam analisadas por esta pesquisadora, que também foi coordenadora do Programa PID-NAILI. 


\section{Representação dos monitores em relação aos seus potenciais alunos (Am, AP, H, M)}

Finalmente, veremos abaixo um movimento identificatório, no qual os monitores se distanciam do lugar de aluno e se posicionam como detentores do poder de professor-avaliador. É um momento de identificação com a imagem de autoridade de monitor em relação aos alunos do projeto; sentimento de segurança para impor-se em uma relação de poder, de desigualdade entre alunos e monitores, e de igualdade e camaradagem entre os monitores. Ainda assim, é possível observar na orientação dialógica os posicionamentos de desigualdade entre as imagens dos monitores mais experientes e dos menos experientes.

Trata-se de uma reunião entre monitores ${ }^{9}$ sendo observada pelo aluno de IC que toma notas. Eles estão corrigindo e comentando as provas de um "teste de nivelamento" aplicado pelos professores do primeiro período de inglês. A produção desse discurso deve-se ao fato que, dependendo da nota, o professor da disciplina de inglês sugere ao aluno que cancele a matrícula na disciplina de inglês e se matricule em outra língua em estágio inicial e procure o centro de extensão de línguas da FALE e o NAILI; ou que mantenha a matrícula e ainda procure a ajuda da monitoria; ou ainda, que cancele a matrícula e faça o teste de Aproveitamento de Estudos para adiantar o curso. As aulas de monitoria do PID, na época, eram de nível intermediário e atendiam aos alunos que cursavam a disciplina de inglês do primeiro período. As aulas de monitoria do NAILI eram de nível pré-intermediário e atendiam aos alunos que eram aconselhados a cancelar a matrícula e estudar nos cursos de extensão até conseguirem acompanhar a disciplina de inglês do primeiro período.

$\mathrm{O}$ monitor $\mathrm{M}$ foi um dos primeiros selecionados para o projeto, tendo em princípio trabalhado como monitor dos alunos do PID. Após o término de sua bolsa PID, ele retornou como monitor do NAILI. Vejamos a sequência:

$\mathrm{H}$ - Pela letrinha ruim eu pensei que ele tinha ido mal na prova/ mas ele fez mais de $90 \%$ em tudo// (risos) pela redação a gente vê se ele colou na proval AP - Olha este aqui (e lê) - to enter the best university of Minas Gerais (todos riem)

Am - Tem "of the world"

(todos riem)

\footnotetext{
${ }^{9}$ Nos enunciados a seguir, há a inclusão de mais uma monitora, denominada $\mathrm{Am}$.
} 
$\mathrm{AP}$ - Eles entram aqui e se acham/

(continuam as correções)

Am - Jesus/ essa realizou o sonho mesmol

$\mathrm{M}$ - Com o tempo vocês se acostumam com films without legends and musics with letters (riso) // sempre aparecel

Am - Saudades M?

$\mathrm{M}$ - Que isso/ Nós somos fundadores do PID/ o PID é uma parte viva de $\underline{\text { mim que anda por aíl }}$

Acima, na representação que os monitores têm do PID e do NAILI, é possível observar, nos dizeres que detêm o efeito da experiência de $\mathrm{M}$ (vocês se acostumam... sempre aparece...) e, em seguida, na pergunta da mais recente monitora Am (Saudades, M?), e na posição enunciativa da resposta de M, que o PID, com seus monitores, detém o efeito de maior status do que o NAILI, com seus monitores.

$\mathrm{Na}$ orientação dialógica das posições enunciativas (sublinhado), os dêiticos nós [monitores] somos autoridade e ele(s) [alunos] são inexperientes e ingênuos; eu/nós/mim $[\mathrm{M}]$ sou/ somos experientes e autoridades e vocês [H, $\mathrm{A}, \mathrm{AP}]$ não possuem a experiência e a autoridade dos fundadores. $\mathrm{O}$ sentido de autoridade na sociologia é considerado como "direito (ou pelo menos poder estabelecido) de decidir ou de comandar". $\mathrm{Na}$ acepção que nos interessa, do ponto de vista prático, opõe-se, por consequência, "o argumento de autoridade às razôes que se tiram da experiência ou da demonstração lógica" (LALANDE, 1996, p. 117). Silva (2000) destaca que, para os Estudos Culturais, a autoridade se diz dos atores sociais que se impóem como superiores por sua posição privilegiada em uma relação de poder.

Essas posições enunciativas também carregam dizeres da FD Excludente (NEVES, 2002), em que a falta inaceitável se mostra na identificação da letra ruim com ir mal na prova. Desse modo, é possível afirmar que nesse processo o que há é a reprodução na qual se perpetuam as identificaçōes: o bom aluno que deve ser copiado à imagem do bom professor que não erra e fala "como um nativo" e que, assim, despreza e expõe os erros do aluno que não sabe, ou que burla (cola na prova), ou que "diz bobagens".

\section{Considerações finais}

O que busquei demonstrar nas análises apresentadas é como os sentidos vão se fazendo nas relações que os alunos/monitores estabelecem entre si, com seus professores e seus alunos nas aulas de monitoria e seu objeto de estudo e 
ensino, a língua estrangeira, no "espaço vazio" (GARCIA, 2001) do acaso de seu processo identificatório. Os traços que marcam as posiçōes de cada monitor são explicitados no discurso em momentos nos quais podemos flagrar representações que remetem a identificações sempre inconscientes, introjetadas a partir do outro, provocando reações de aproximação, recusa, distanciamento, como já ressaltou Coracini (2003) e, portanto, não necessariamente harmoniosa ou facilitadora, como explica Garcia.

M, por exemplo, em seu modo de falar marcado por modalizações autonímicas interrogativas, dialoga com suas palavras, buscando fixar o efeito que ressoa como "ser bom aluno ou professor é querer". H, por sua vez, denuncia no lapso seu desejo de ser native-like em lugar de ter conhecimento excelente. Na ressonância dos verbos "procurar quem sabe mais" e "conhecer os erros", o efeito produzido é de oscilação entre poder errar, experimentar na posição-aluno e poder sanar os erros na posição-professor/nativo. Essas identificações se referem ao idealizado conhecimento teórico do bom professor e conhecimento linguístico do nativo. AP, por outro lado, aponta, através do lapso, uma identificação ainda bastante marcada com o traço da posição-aluna, distanciando-se da posição-professor e que ressoa no dizer da falta: "se perder", "não ter respostas", "não ser tão aplicada". Dessa forma, também a sua representação de professor é daquele que não pode correr o risco de errar, de se perder, denunciando, assim, a sua posição mais marcadamente faltosa. Entendo também que essas posições enunciativas revelam a diferença sexual cristalizada na cultura na qual a jovem se identifica mais com a posição feminina da falta, com o não-saber, e os dois jovens se articulam mais com o significante da excelência, do "querer é poder". Ressalvo, entretanto, que essas posições não se referem ao gênero masculino ou feminino, mas ao discurso que os rege.

Cabe ainda marcar, na constituição desses sujeitos, em suas práticas de exercício da autoridade de avaliadores, discursos atravessados pela FD Excludente, em que a imperfeição exclui o sujeito do grupo ideal. Poderíamos supor que a recorrência da expressão "correr atrás", bem como do verbo "procurar" e do substantivo "dificuldade", são significantes que alienam esses três enunciadores ao ponto da falta própria a todo sujeito, não necessariamente ao sexo feminino, e que na busca de sua identidade profissional oscilam entre posições assumidas ou negadas, assim construindo amarras à necessária identificação com esse idealizado professor/falante da LE.

Finalmente, proponho que se busque problematizar o processo de formação do futuro professor não só em programas de monitoria como este, 
mas também em relação à aprendizagem em geral. Sempre é bom lembrar que os professores, no lugar de modelos e formadores, protagonizam primordialmente o nível da identificação à imagem e ao significante, ou seja, ao se reproduzirem os modelos a serem replicados, perpetua-se, nos alunos, a identificação a pessoas ou a algum de seus traços. Como alertam Riolfi e Alaminos (2007), apresentamo-nos como mapas delimitando o caminho que o aluno deve trilhar para chegar ao mesmo destino que nós e inconscientemente nos reconhecemos nas produções dos alunos ou monitores a partir de quando são feitas do modo como nós próprios faríamos.

Os monitores que participaram desta pesquisa seguem em seu processo identificatório e podem dar sequência a um modus operandi que parece ser reproduzido em gestos de interpretação que definem o que é ser um bom professor, um bom aluno, como tratar o erro, como se deve saber a língua, entre outros. Entretanto, acredito que é o desejo mesmo que movimenta o sujeito a construir um lugar singular, vai mexendo e deslocando suas identificações e levando-o a se reinventar sempre que o estado atual de reprodução possa não mais lhe satisfazer.

\section{Referências}

AUTHIER-REVUZ, J. Entre a transparência e a opacidade. Porto Alegre: EDPUCRS, 2004.

AUTHIER-REVUZ, J. Les formes Du discours rapporté. D.R.L.A.V., Université de Paris, v. VIII, n.17, p.1-88, 1978.

AUTHIER-REVUZ, J. Palavras incertas. Campinas: Ed. Unicamp, 1998.

CORACINI, M. J. Apresentação. In: Identidade e discurso. Campinas: Ed. Unicamp/Argos, 2003. p. 13-19.

CORACINI, M. J. Identidade e discurso. Campinas: Ed. Unicamp/Argos, 2003. p. $223-235$

FOUCAULT, M. As palavras e as coisas: uma arqueologia das ciências humanas. 3. ed. São Paulo: Martins Fontes, 1985.

FOUCAULT, M. A arqueologia do saber. 5. ed. Rio de Janeiro: Forense Universitária, 1997.

FREUD, S. Um caso de histeria. Três ensaios sobre a teoria da sexualidade e outros trabalhos, v. 2, 1901-1905. CD-ROM. (Edição eletrônica das obras psicológicas de Sigmund Freud).

FREUD, S. (1925). Die Verneinung. Revue Fr. De Psychanalyse, 7, p. 174-177, 1934. 
GARCIA, C. Psicanálise e Educação. In: LOPES, E. M. T. (Org.) A Psicanálise escuta a Educação. Belo Horizonte: Autêntica, 2001. p. 11-33.

GRIGOLETTO, M. Representação, identidade e aprendizagem de Língua Estrangeira. In: CORACINI, M. J. Identidade e discurso. Campinas: Ed. Unicamp / Argos, 2003. p. 223-235.

HALL, S. Quem precisa de identidade? In: SILVA, T. T. (Org.) Identidade e diferença: a perspectiva dos estudos culturais. Petrópolis: Vozes, 2000. p. 103-133. HAROCHE, C. L'Ellipse (manque nécessaire) et l'incise (ajout contingent) Le statut de La détermination dans Le grammaire ET son lien à La subjectivité. Matérialités discursives. Lille: Presses Universitaires, 1981. p. 149-154

LACAN, J. J. O Seminário. Livro 20: Mais, ainda. Trad. M. D. Magno. Rio de Janeiro: Jorge Zahar, 1985.

LACAN, J. J. Função e campo da fala e da linguagem em psicanálise. In: Escritos. Trad. Vera Ribeiro. Rio de Janeiro: Jorge Zahar, 1998.

LACAN, J. J. (1961-1962). Le séminaire de Jacques Lacan. Livre IX: L'Identification. Publication hors commerce Document interne à l'Association freudienne internetionale et destiné à ses membres, 1998.

LALANDE, A. Vocabulário técnico e crítico da filosofia. 2. ed. São Paulo: Martins Fontes, 1996.

LOPES, E. M. T. (Org.) A Psicanálise escuta a Educação. Belo Horizonte: Autêntica, 2001. p. 71-106.

MENDONÇA FILHO, J. B. Ensinar: do mal entendido ao inesperado da transmissão. In: LOPES, E. M. T. (Org.) A Psicanálise escuta a Educação. Belo Horizonte: Autêntica, 2001. p. 71-106.

NEVES, M. S. Processo discursivo e subjetividade: vozes preponderantes na avaliação da oralidade em língua estrangeira no ensino universitário. 2002. 276 f. Tese (Doutorado em Linguística Aplicada)-Instituto de Estudos da Linguagem, Universidade Estadual de Campinas, Campinas, 2002.

PÊCHEUX, M. Semântica e discurso: uma crítica à afirmação do óbvio. 2. ed. Campinas: Ed. Unicamp, 1995.

PÊCHEUX, M. O discurso: estrutura ou acontecimento. 3. ed. Campinas: Pontes, 2002.

REVUZ, C. A língua estrangeira entre o desejo de um outro lugar e o risco do exílio. In: SIGNORINI, I. (Org.) Lingua(gem) e identidade. Campinas: Mercado de Letras, 1998. p. 213-230. 
RIOLFI, C.; ALAMINOS, C. Os pontos de virada na formação do professor universitário: um estudo sobre o mecanismo da identificação. Educação e Pesquisa, São Paulo, v. 33, n. 2, p. 297-310, 2007.

SERRANI, S. M. Abordagem transdisciplinar da enunciação em segunda língua: a proposta AREDA. In: SIGNORINI, I.; CAVALCANTI, M. C. (Org.) Linguistica aplicada e transdisciplinaridade. Campinas: Mercado de Letras, 1998. p. 143-167.

SERRANI, S. M. Resonancias discursivas y cortesía en prácticas de lectoescritura. D.E.L.T.A., PUC-SP, v. 17, n. 1, p. 31-58, 2001.

SERRANI, S. M. Discurso e cultura na aula de língua. Campinas: Pontes, 2006.

SIGNORINI, I. (Org.). Lingua(gem) e identidade. Campinas: Mercado de Letras, 1998. p. 213-230.

SILVA, T. T. Teoria cultural e educação: um vocabulário crítico. Belo Horizonte: Autêntica, 2000.

TEIXEIRA, M. Análise de Discurso e Psicanálise. Porto Alegre: EDIPUCRS, 2005.

WOODWARD, K. Identidade e diferença: uma introdução teórica e conceitual. In: SILVA, T. T. (Org.) Identidade e diferença: a perspectiva dos estudos culturais. Petrópolis: Vozes, 2000. p. 7-72.

Recebido em março de 2009. Aprovado em julho de 2009. 